\title{
Impact of Climate Change on Yields of Wheat in Ethiopia: An Augmented Cobb-Douglas Production Function Approach
}

Abera Gayesa Tirfi ( $\sim$ abera.gayesa@gmail.com )

UNISA, Ethiopia Regional Learning Centre https://orcid.org/0000-0002-6267-1366

Abayomi Samuel Oyekale

North-West University - Mafikeng Campus

\section{Research Article}

Keywords: Climate Change, Wheat Yield, Cobb-Douglas Functional Model, Ethiopia

Posted Date: February 8th, 2022

DOI: https://doi.org/10.21203/rs.3.rs-1296215/v1

License: (c) (i) This work is licensed under a Creative Commons Attribution 4.0 International License.

Read Full License 


\title{
Impact of Climate Change on Yields of Wheat in Ethiopia: An Augmented Cobb-Douglas Production Function Approach
}

\begin{abstract}
The study analyzed the impact of climate change on yields of wheat crop in Ethiopia by employing Cobb-Douglas Production Function Approach using time series data for the period 1981 - 2018. The study confirmed that long-season rainfall and crop growing season maximum temperature have negative and significant effects on wheat yield. The result implies that a rise in maximum temperature during crop growing period and variation in long-season rainfall could have adverse impact on yield of wheat crop. The findings further showed that fertilizers, improved seed, and irrigation applied on wheat crop have all positive and significant impact on yield of wheat, implying that use of fertilizer, improved seed and irrigation inputs have vital role in increasing yields of wheat crop. Conversely, the study indicated that land area cultivated under wheat cropping showed negative and significant impact on yield of wheat crop, implying that any area expansion under wheat crop production would have negative impact. In view of the findings of the study, it is recommended that adaptation strategies that could offset the adverse effects of climate change should be designed and adopted. An increased use of irrigation is recommended, particularly in potential lowland areas to mitigate the adverse effect of climate sensitivity on wheat crop. Use of improved wheat seed varieties of short duration and tolerant to warm and moisture stress conditions are recommended to increase productivity and production of wheat crop. Increased use of fertilizers in cooler mid and highland areas can be another option to increase the productivity of wheat crop in Ethiopia.
\end{abstract}

Keywords: Climate Change, Wheat Yield, Cobb-Douglas Functional Model, Ethiopia

\section{Introduction}

Wheat is among the most important food crop in Sub-Saharan Africa (SSA), occupying a cultivated land area of 2.9 million hectares and production volume of 7.5 million tons (FAO, 2017). The most important producers of wheat in SSA include: South Africa, Ethiopia, Sudan, Kenya, Tanzania, Nigeria, Zimbabwe, and Zambia in descending order.

Ethiopia is considered as the second biggest producer of wheat in SSA, next to South Africa with about 0.88 million ha cultivated land area and total production of 4.63 million tons (White, et al., 2001). In Ethiopia, wheat is considered as the fourth most important cereal crop in terms of both area cultivated and volume of production after teff, maize and sorghum (CSA, 2018). Wheat crop is largely grown in the highlands as well as mid-highlands (Dega and Weyna Dega agro-climatic zones), which lie amid 7.05 and 
$13.3^{\circ} \mathrm{N}$ latitude and 37.5 and $42.2^{\circ} \mathrm{E}$ longitude, at an elevations ranging from 1,500 to 3,200 meters above sea level (Hailu, 1990). As a cool-weather cereal crop, the major wheat growing belts are Oromia (i.e., Arsi, Bale and Shewa) and Amhara (East and West Gojam) highlands of the country. The crop is mostly grown during the main rainy (longrainfall) season from June - September and harvested from October through January. The crop also grows during the short-rainy season in all Shewa zones as well as in North and South Wollo zones, the season which contributes about 5 - 10 percent of cereal output. increased intensity of abiotic (drought, heat) and biotic (diseases and pests) stresses have adversely reduced production and yield of wheat (Tadesse, et al, 2018). East African countries as Sub-Saharan Africa; Ethiopia, Kenya and Tanzania showed an increasing tendency in extreme temperature indices, and irregular rainfall patterns (Gebrechorkos, et al. 2018). The growth and yield of wheat crop is adversely affected by environmental stresses such as high temperature, soil moisture deficit, low light intensity etc and among these stresses high temperature is the crucial one (Modarresi et al, 2010; Kajla et al., 2015).

The adverse and negative impacts of climate change on wheat crop explained in the problem statement, therefore, needs to be studied and analyzed in-depth. In Ethiopia, such studies are inadequate, particularly aggregately at national level (Deressa, 2007). Most of the available studies were confined to some regions and local areas. For instance, Bekele, et al (2017) investigated the effect of rainfall on wheat yield in Sinana Woreda of Ethiopia. Yibrah, Korecha, and Dandesa (2018) conducted a study to characterize past rainfall and temperature variability and their effects on wheat and barley production in Enderta district, Tigray region of Ethiopia using decadal rainfall and temperature data covering the period 1984-2014. Shumate, et al (2017) conducted research to identify the impact of climate variability on cool weather cereal crops (wheat and barley) yield in Central Highlands and Arssi farming systems of Ethiopia. In view of these facts, this study was undertaken to narrow the research gap observed on wheat yield analysis aggregately at nationally level. Therefore, the objective of the study was to analyze the 
71 impact of climate change on yields of wheat in Ethiopia. The results are expected to be

72 useful for informing management practices at national and regional levels and can be

73 used to design strategies that sustain wheat production in the country.

\section{Materials and Methods}

According to Library of Congress (2005), Ethiopia is located in Eastern Africa. It borders Sudan on the west, Eritrea on the north, Djibouti and Somalia on the east, Kenya on the south, and South Sudan on the south west. Geographically, Ethiopia lies between the Equator and Tropic of Cancer, between the $3^{\circ} \mathrm{N}$ and $15^{\circ} \mathrm{N}$ Latitude or $33^{\circ} \mathrm{E}$ and $48^{\circ} \mathrm{E}$ Longitude. The country has a total area of about 1.127 million square kilometers. Administratively, Ethiopia is structured into nine Regional States and two City Administrative Councils. Based on United Nations (2020) population projection, the current population of Ethiopia is about 114.44 million with an annual growth rate of 2.7 percent.

\subsection{Description of the study area}

The major cereal crops including wheat are mainly grown in the traditional climatic zones of Ethiopia (Dessie, 2018). Wheat, the focus of this study, is largely grown in the Ethiopian highlands, which lie between 6 and $16^{\circ} \mathrm{N}$ and 35 and $42^{\circ} \mathrm{E}$, at altitudes ranging from 1500 to 3200 meters above sea level (Hailu, 1991). The most suitable areas for wheat production, however, fall between 1900 and 2700 masl. In the highlands, rainfall distribution is bimodal and ranges between 600 and $2000 \mathrm{~mm} / \mathrm{annum}$.

In Ethiopia, wheat is grown primarily as a rainfed crop by smallholders in the highlands. In most of the country, only a single wheat crop is grown during the second, longer rainy season (meher) which usually starts in June. The short-season rains (belg), starting in February, are less reliable in most parts of Ethiopia; however, in the southeast of the country (e.g., Bale zone of Oromia Region), rainfall distribution is bimodal. Growing wheat in short-season implies harvesting during long-season, which often results in high grain moisture levels and sprouting. Thus, wheat crops are typically sown by broadcasting in June or July and harvested in November or December (Hailu, 1991). 
In general, wheat is a cool-weather grain crop that is commonly grown in the highlands and mid-highland area of the country at elevations ranging from 1,500 to 2,800 meters above sea level, with major wheat growing belts in Oromia (i.e., Arsi, Bale and Shewa) and Amhara (East and West Gojam) highlands of the country. The crop is grown mostly during the main rainy season (meher) from June to September and harvested from October through January.

\subsection{Data Type and Method of collection}

In this study, the researcher used time series secondary data of all the variables. The type of data considered in this study included: climate variables, aggregate yield and cropped area under wheat, fertilizer and improved seed used in wheat crop production.

Data on weather conditions (temperature and precipitation) for the period from 1981 to 2018 were mainly taken from the National Meteorological Agency (NMA) of Ethiopia. Data for 12 representative weather stations based in major wheat growing belts were selected from Oromia and Amhara Regional States, as these two regions accounted for $85.8 \%$ of the total cultivated area and $87.9 \%$ of production of wheat during $2017 / 18$ production year (CSA, 2019). For precipitation, average monthly data for Short-Season (F-M) and Long-season/ Kiremt/ main crop season, (J-S) were taken as recorded in NMA database. For temperature, crop growing season (February - September) mean minimum and maximum temperatures were taken as recorded in NMA database.

For wheat crop data, nationally aggregated data on area cultivated, yield per hectare, fertilizer and improved seed applied, and area irrigated under wheat crop were compiled from CSA subsequent publications or website covering the period from 1981 to 2018. Any gap in these variables was complemented from Food and Agriculture Organization (FAOSTAT) database.

\subsection{Empirical Model Specification}


In order to address the objective of this study, augmented Cobb-Douglas

135 Production Functional model has been employed to estimate the regression coefficient for the mean yield function, $f(x)$.

137

In line with the production theory, it is more likely that the relationship between climate and non-climate variables and crop yield takes non-linear form (Afzal, et al, 2017; Mahmood, et al, 2012; Chen, et al, 2004 and Just and Pope, 1979). According to Chen, et al (2004) and Just and Pope (1979), the model provides more significant results compared to linear functional form. The model assumes that crop productivity (yield) is a function of endogenous variables like irrigated area under crops, application of fertilizers, utilization of labours and use of tractors; and exogenous factors like literacy rate, farm harvest price of specific crops.

Furthermore, model assumes that agricultural production is a function of many endogenous and exogenous variables like cultivated area, irrigated area, fertilizers, improved seed, etc. The Cobb-Douglas production function, in its stochastic form (Gujarati, 2004), can be expressed as:

$$
\mathrm{Y}_{t}=\mathrm{AX}_{1}^{\beta 1} X_{2}^{\beta 2} \ldots X_{n}^{\beta n \text { e } \varepsilon}
$$

Where, $Y_{t}$ is a dependent variable (yield of wheat), $X_{s}$, are vectors of independent variables included in the regression analysis and $\beta_{s^{\prime}}$ are parameters to be estimated. $A$ is constant term, $e$ is base of natural logarithm and $\varepsilon$ is the error term with zero mean and constant variance. This non-linear form of Cobb Douglas production function can be estimated through ordinary least squares by taking natural log on both sides of equation (2.1), which becomes log-linear form. Estimates of this form of production function give direct elasticities of variables. The log-linear form of Cobb Douglas production function in this regard is expressed as:

$$
\ln Y_{i}=\beta+\beta \mathrm{i} \sum_{i=1}^{n} \ln \mathrm{X}_{\mathrm{i}}+\varepsilon \mathrm{i}
$$

Where $\ln Y_{t}$ shows wheat yield (quintal per hectare) at time $\mathrm{t}, \mathrm{X}_{\mathrm{i}}$ is vector of farm inputs including cropped land area, fertilizer, improved seed, irrigated area, etc. However, time series data were unavailable for some of the farm inputs like farm machinery, oxen 
power, and laborers. In its functional form, the Cobb-Douglas production function under equation (2.2) is specified as:

$$
\ln Y_{t}=\alpha_{0}+\beta_{1} \operatorname{lnLa} t+\beta_{2} \operatorname{lnFert} t+\beta_{3} \ln I_{S_{t}}+\beta_{4} \ln \operatorname{Irrga}_{\mathrm{it}}+\varepsilon_{\mathrm{t}}
$$

where, $\ln Y_{t}$ is the natural $\log$ of yield of wheat (kilogram per hectare), $\operatorname{lnLat}$ is natural $\log$ of cropped land area under wheat crop, lnFertt is natural log of fertilizer used under wheat crop, $I_{t}$ is natural log of improved seed used under wheat crop, and Irrgat is natural log of irrigated land area under wheat crop at time $t$.

The Cobb-Douglas production model further assumes that climatic factors are input factors for yield of crops (Nastis et al., 2012). Climatic variables considered in this study were rainfall and temperature, where mean minimum and maximum temperatures for crop growing period (i.e. February to September), and mean rainfall for Short(FMAM) and long-seasons (JJAS) were considered. $\varepsilon$ is the usual error term independently and identically distributed. After incorporating climatic variables, equation (2.3) in its log-linear form has been specified as follows:

$$
\begin{aligned}
& \ln Y_{t}=\alpha_{0}+\beta_{1} \operatorname{lnLat}+\beta_{2} \ln \text { Fert }_{\mathrm{t}}+\beta_{3} \ln \mathrm{SS}_{\mathrm{t}}+\beta_{4} \operatorname{lnIrrgat}+\beta_{5} \ln \text { SSRainfall } \mathrm{t}+ \\
& \beta_{6} \operatorname{lnLSRainfall}_{\mathrm{t}}+\beta_{7} \operatorname{lnMinTemp} \mathrm{ln}_{\mathrm{t}}+\beta_{8} \operatorname{lnMaxTemp}_{\mathrm{t}}+\varepsilon_{\mathrm{t}}
\end{aligned}
$$

Where: $\ln Y_{t}$ is the natural $\log$ of yield of wheat (kilgram per hectare), $\operatorname{lnLat}$ is natural $\log$ of cropped land area under wheat, lnSSRainfallt is natural log of short-season season rainfall, lnLSRainfallt is natural log of long-season rainfall, lnMinTemp $p_{t}$ is natural $\log$ of crop season mean minimum temperature recorded during cropping seasons, $\operatorname{lnMaxTemp} p_{t}$ is natural $\log$ of crop season mean maximum temperature recorded during cropping seasons, $\operatorname{lnFert}$ is natural $\log$ of fertilizer used under wheat, $\operatorname{lnIS}_{t}$ is natural $\log$ of improved seed used under wheat, Irrgat is natural $\log$ of irrigated area under wheat, $\mathrm{t}=$ time period from $1981-2018, \alpha_{0}, \beta_{1}, \beta_{2}, \beta_{3}, \beta_{4}, \beta_{5}, \beta_{6}, \beta_{7}$, and $\beta 8$ are unknown parameters to be estimated, and $\varepsilon_{t}$ is the error term.To estimate the Cobb-Douglas production model specified by equation 2.4, MedCal-Version 19.1 software and SPSS 24 Statistical packages were used. 


\subsection{Methods of Estimation and Test for Time Series Properties}

198

199

200

Wheat crop yield model selected for this study has been estimated by ordinary least squares method. The models have been estimated consistently by Ordinary Least Squares (OLS) if the error term $\left(\varepsilon_{\mathrm{j}}\right)$ is a white noise process or more generally, if the error term has a zero mean, constant variance and uncorrelated with the explanatory variables and its previous realizations.

The models have been estimated using annual time series data for the period between 1981 and 2018. Prior to model estimation, the data series have been subjected to various tests to confirm various properties required for OLS to give results that are efficient and consistent.

Since this study uses time series data, it was necessary that, before estimation of the equations, the series be tested for satationarity/ unit root and existence of cointegration using appropriate methods and tools. In this study, two widely used methods were chosen: Augmented Dickey-Fuller (ADF) test (Dickey and Fuller, 1979) and Phillips-Perron (PP) test (Phillips and Perron, 1988) to check the presence of unit roots in the data series. The ADF test for stationarity in a series $y$ involved estimating the equation:

$$
\Delta \mathrm{y}_{\mathrm{t}}=\mu+\beta_{\mathrm{t}}+\gamma \mathrm{y}_{\mathrm{t}-\mathrm{i}}+\sum_{i=1}^{p} \emptyset_{\mathrm{i}} \Delta \mathrm{y}_{\mathrm{t}-\mathrm{i}}+\varepsilon_{\mathrm{t}}
$$

Where $\mu$ is the drift (intercept), $t$ is the trend, $i$ is equal the number of lags in $\Delta y_{t-i}, p$ is the maximum number of lags determined using Akaike Information Criterion (AIC) and Schwartz Criterion (SC) and $\varepsilon_{\mathrm{t}}$ is the random error term. The null hypothesis $H_{o}: \gamma=0$ (unit root) was tested against the alternative hypothesis $H_{A}: \gamma<0$ (no unit root). If the computed test statistic was found greater than the critical value then the null hypothesis was not rejected. If $H_{O}$ could not be rejected, then the time series variable contained a unit root and hence non stationary, otherwise it was stationary. If its first difference is 
227 then tested and found stationary, the series was concluded to be an I(1) (Green, 2008;

228 Gujarati, 2004; Dickey and Fuller, 1979).

229

230

231

232

233

234

235

236

237

238

239

240

241

242

243

244

245

246

247

248

249

250

251

252

253

254

255

256

Time series were also subjected to a Phillips -Perron (PP) test which has a higher power. The PP test took the form:

$$
\Delta \mathrm{Y}_{\mathrm{t}}=\theta_{0}+\sum_{i=1}^{m} \delta_{\mathrm{i}} \Delta \mathrm{Y}_{\mathrm{t}-\mathrm{i}}+\varepsilon \mathrm{t}
$$

Where $\Delta Y_{t}$ was the first difference of the dependent variable; $i$ is the number of truncation lags, where $i=1,2, \ldots, m ; \theta$ and $\delta$ are coefficients and $\varepsilon_{\mathrm{t}}$ is the error term. The null hypothesis of, $H_{0}: \delta_{i}=0$ (unit root) was tested against the alternative, $H_{A}: \delta_{i}<0$ (no unit root). If the computed test statistic was found greater than the critical value at $5 \%$ level of significance then the null hypothesis could not be rejected. If $H_{O}$ could not be rejected, then the time series variable contained a unit root and hence non stationary, otherwise it was stationary.

\section{Results and Discussion}

\subsection{Results of the Time Series Unit Root Test}

Unit root, Cointegration and related diagnostic tests have been performed before estimation of the Cobb-Douglas Production equation. The major reason for conducting such tests was to establish the order of integration, crucial for setting up the econometric models from which implications are made. Since most of the economic data are non stationary, OLS regression based on such data is likely to give spurious results. Thus, all the series used in this study were tested for presence of a unit root based on ADF and PP.

Table 3.1 presents the results of the stationarity tests on unit root by employing Augmented Dickey Fuller (ADF) and Phillip Pherron (PP) unit root test of order of integration. 
The unit root test results, indicate that the following variables are stationary at order $(\mathrm{I}(0))$ : $\log$ wheat yield, log area under wheat; log fertilizer quantity used in wheat growing areas, and log irrigated area under wheat.

Conversely, the following variables were found to be integrated of order (I(1)): log improved wheat seed; log mean rainfall, and crop growing period mean minimum and maximum temperatures in wheat growing areas. Thus, the variables used in the study are a mixture of $\mathrm{I}(0)$ and $\mathrm{I}(1)$. In case time series data exhibit a mixture of $\mathrm{I}(0)$ and $\mathrm{I}(1)$ some researchers and econometricians recommend Cobb-Douglas or ARDL modeling as best approach (Sharma and Singh, 2019 and Dushko, et al 2011). In order to employ ARDL approach, bounds test of integration, model stability test and variance error correction model (VECM) should be conducted to test presence of long-term cointegration (Sharma and Singh, 2019). In case of Cobb-Douglas production model similar tests are conducted as ARDL model (Dushko, et al 2011). Cobb-Douglas model further needs VAR stability, serial correlation (LM), multicolinearity, Heteroscedasticity, Wald F-statistic, stability and RESET Tests.

Table 3.1: Time Series Unit Root Test Results for Wheat Yield and Related Independent

\begin{tabular}{|l|c|c|c|c|c|}
\hline \multirow{2}{*}{ Variable } & \multicolumn{2}{|c|}{ ADF } & \multicolumn{2}{c|}{ PP } & \multirow{2}{*}{ Outcome } \\
\cline { 2 - 6 } & Level & First Diff. & Level & First Diff. & \\
\hline LNWY & $-0.2925 * * *$ & -1.8247 & $-0.2925^{* * *}$ & -1.3252 & $\mathrm{I}(0)$ \\
\hline LNWAR & $-0.27204 * * *$ & -1.10663 & $-0.27204^{* * *}$ & -1.10663 & $\mathrm{I}(0)$ \\
\hline LNWIMS & -0.91607 & $1.67292^{*}$ & -0.91608 & -1.4504 & $\mathrm{I}(1)$ \\
\hline LNFERTW & $-0.59566^{* * *}$ & -1.2101 & $-0.59566^{* * *}$ & -1.21014 & $\mathrm{I}(0)$ \\
\hline LNIRRGAW & $-0.44296^{* * *}$ & -1.43478 & $-0.44296^{* * *}$ & -1.43478 & $\mathrm{I}(0)$ \\
\hline LNMEANRF & -1.27530 & $0.49852^{* *}$ & -1.27530 & -1.56314 & $\mathrm{I}(1)$ \\
\hline LNMINTEMP & -0.75834 & $0.405839^{* * *}$ & -0.758336 & -1.27162 & $\mathrm{I}(1)$ \\
\hline LNMAXTEMP & -0.90770 & $0.47402 * * *$ & -0.90771 & -1.49304 & $\mathrm{I}(1)$ \\
\hline
\end{tabular}


According to McCarl et al., (2008) variables with I(1) must be differenced first before estimation. Since most of the variables are not integrated at the same order under the models, a multiple regression analysis using OLS method with the differenced variables was performed (Gujrati, 2004). The test for cointegration involved running a regression of $\log$ wheat yield. Residual series were obtained from the estimated equations and tested for the presence of unit root. The null hypothesis of existence of a unit root, which implies there is no cointegration, was rejected at 5\% level of significance for the estimated residuals. The cointegration test results are shown in Table 3.2. The results show that linear combination of the variables in each regression was stationary. The results indicate existence of a long-run relationship among variables in the models.

Table 3.2: Result of Cointegrating Test for wheat output data series

\begin{tabular}{cccl}
\hline \multicolumn{1}{c}{ Type of Test } & Test Statistic & Critical Values & \multicolumn{1}{c}{ Conclusion } \\
\hline Wald Test & $-5.3689 * *$ & 4.130 & $\begin{array}{l}\text { Long-run Cointegration } \\
\text { exists }\end{array}$ \\
\hline
\end{tabular}

** implies significant at $5 \%$ level

Residual based tests were carried out on all residual series from the output response equation. Normality, serial correlation and heteroscedasticity tests were also performed. The results are presented in Table 3.3. From the histogram-, normality tests the probability values ( $\mathrm{P}$ values) of the Jarque Bera statistic are greater than 0.05 and thus the null hypothesis that standardized residuals are normally distributed could not be rejected at 5 percent level of significance. This implied that the series is normally distributed and $t$ and $\mathrm{F}$ tests are used for hypothesis testing as they assumed normal distribution.

The Breush-Godfrey Lagrange Multiplier (LM) test for serial correlation was also carried out and the results show no evidence of autocorrelation. The probability (P) associated with the computed test statistic is greater than 0.05 and thus the null hypothesis of no serial correlation in the residuals could not be rejected at 5 percent level of significance. To ascertain whether the standard errors of the estimates are biased the the equations. The $\mathrm{P}$ value associated with the computed test statistic is greater than 0.05 
and thus the null hypothesis of homoscedasticty, could not be rejected at $5 \%$ level of significance.

Table 3.3: Residual Properties of Wheat Yield Response Equation

\begin{tabular}{|c|c|c|c|}
\hline Type of test & Test statistic & $\begin{array}{c}\text { Test statistic } \\
\text { value }\end{array}$ & Probability \\
\hline Normality test-histogram & Jarque Berra & 0.23650 & 0.8885 \\
\hline $\begin{array}{l}\text { Breusch-Godfrey Serial } \\
\text { Correlation LM Test }\end{array}$ & Obs*R-squared & 0.55634 & 0.7572 \\
\hline $\begin{array}{l}\text { Heteroskedasticity Test: } \\
\text { ARCH }\end{array}$ & Obs*R-squared & 2.62662 & 0.1051 \\
\hline
\end{tabular}

313

Furthermore, Ramsey RESET test has been conducted on the response equations to test whether non linear combinations of fitted values help to explain the dependent variable. The intuition is, if non linear combinations of the explanatory variable have any power in explaining the dependent variable, the model is misspecified and violates the assumptions of the classical normal linear regression. Table 3.4 presents the results of the Ramsey Reset tests. The findings show that the $\mathrm{P}$ values are greater than 0.05 and thus unable to reject the null hypothesis that the powers of the dependent variable have zero coefficients. This implies that the functional form of the models is correctly specified ruling out the possibility of specification errors in the models.

determine parameter constancy, recursive estimations were performed on the crop response equations. Recursive coefficient tests, CUSUM tests, CUSUM residual squares test, one step forecast test and $\mathrm{N}$ steep forecast tests were performed. The result is presented in Figure 3.1. It can be seen that the plots do not diverge significantly from the zero line and the residuals lie within the standard error band suggesting stability in the parameters of the equation.

Table 3.4: Ramsey Reset Tests Results

\begin{tabular}{lccl}
\hline Dependant variable & F statistic & Probability & \multicolumn{1}{c}{ conclusion } \\
\hline Log of wheat output & 0.425344 & 0.6582 & $\begin{array}{l}\text { No indication of } \\
\text { misspecification error }\end{array}$ \\
\hline
\end{tabular}




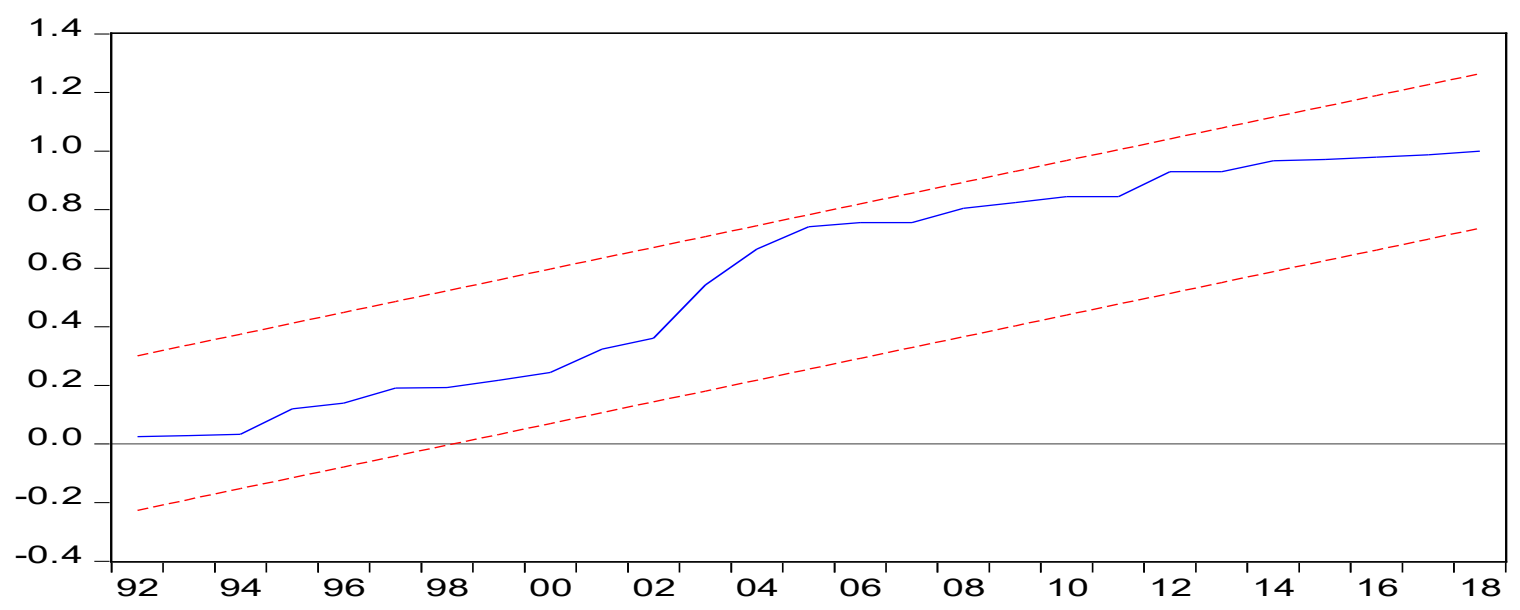

CUSUM of Squares $5 \%$ Significance

Figure 3.1: Recursive Residuals from the Wheat Output Response Equation

\subsection{Modeling Impact of Climate and Socioeconomic Variables on Yield of Wheat}

Augmented Cobb-Douglas Production Functional model was estimated for wheat crop yield specification as unit root tests showed that the regresses were a mixture of $\mathrm{I}(1)$ and $\mathrm{I}(0)$. The test of the data series for serial correlation and multicollinearity showed that there was no serial correlation in the regression models as the Durbin Watson statistic was close to 2 in most cases and the values of VIF are less than 10 for the wheat crop yield model.

The explanatory variables considered in the wheat yield model estimation were climatic variables (short-season rainfall, long-season rainfall, crop growing period mean minimum and maximum temperatures) and non-climatic variables (land area under wheat crop, quantity of fertilizer and improved seed used and irrigated area under wheat cropping system). The wheat yield model has been estimated by employing ordinary least square technique. The estimated coefficients of the Cobb Douglas production function model was significant as the F-value indicated that the overall regression model best fitted to the present data. The adjusted $\mathrm{R}^{2}$ values of 0.777 in the estimated wheat yield model implies that 77.7 percent of the variations in wheat yield model are explained by climate variables (short-season and long-season rainfall, crop growing season mean minimum and maximum temperatures), land area under wheat production, quantity of fertilizer and improved seed consumed, and irrigated area under wheat cropping system. 
in Table 3.5. The results show that long-season rainfall (June to September) and maximum temperature variables during crop growing season (February to September) are negatively associated with yield of wheat and both are statistically significant at 10 percent level of significance. The result implies that a $1 \%$ rise in maximum temperature and change in long-season rainfall during crop growing period would decrease yield of wheat crop by $2.8 \%$ and $0.5 \%$ respectively. The study finding on crop growing period mean maximum temperature and wheat yield is in line with the theory proposition that states a rising temperature may result in reduced agricultural productivity (Sigh and Awais, 2019; Amin, et al, 2015). Warmer temperatures expected with more extreme temperature events will negatively impact on plant and crops productivity such as wheat, barley, cauliflower, apples etc. With regard to long-season rainfall, the theory assumes that more variations in rainfall patterns may adversely affect yield of wheat crop. Amin, et al, (2015) in their study on effects of climate change on yield of major crops in Bangladesh also confirmed that temperature (both maximum and minimum) and rainfall increases beyond their optimum requirement would devastate the yield of Aman rice.

The results of this study are in line with the findings of other researchers (Singh et al, 2017; Shumetie et al, 2017; Ajay and Pritee, 2013). Singh, et al, (2017) found that maximum temperature and rainfall showed negative and significant effect on wheat yield in Gujarat State of India; wheat needs cool, dry and clear climate with an optimum temperature ranging between $14-20^{\circ} \mathrm{C}$. Excessive heat causes reduction in grain number and reduces duration of the grain filling period in wheat, ultimately impacting yield. Shumetie, et al (2017) in their study in Ethiopia also found that the coefficient estimate for wheat growing season rainfall was negative and significant at 10 percent level of significance. According to Ajay and Pritee (2013), any increment in maximum temperature has a negative and statistically significant impact on wheat productivity. Increase in maximum temperature by $1 \%$ would negatively affect wheat productivity by $2.63 \%$. However, the study results of Ajay and Pritee in respect of minimum temperature are conversely related to the current study in which wheat productivity is negatively 
389 affected due to rise in minimum temperature; the regression coefficient for minimum 390 temperature is statistically significant at $1 \%$ significance level and it shows that $1 \%$ 391 increase in minimum temperature negatively affects wheat productivity by $1.73 \%$.

392

393 Table 3.5: Estimates of Cobb-Douglas Production Function from wheat yield model 394

\begin{tabular}{|c|c|c|c|c|c|}
\hline Explanatory Variables & Coefficients & $\begin{array}{c}\text { Std } \\
\text { Errors }\end{array}$ & $\begin{array}{c}\text { T- } \\
\text { Ratio }\end{array}$ & P-Value & VIF \\
\hline (Constant) & 9.1192 & & & & \\
\hline $\ln$ WhArea & $-0.3542 *$ & 0.1955 & -1.812 & 0.0803 & 12.653 \\
\hline $\operatorname{lnFertWh}$ & $0.269 * * *$ & 0.0952 & 2.828 & 0.0084 & 10.458 \\
\hline $\operatorname{lnImSWh}$ & $0.1849 * * *$ & 0.06731 & 2.747 & 0.0102 & 3.354 \\
\hline $\operatorname{lnIrrgArWh}$ & $0.1529 * *$ & 0.06745 & 2.268 & 0.0310 & 3.068 \\
\hline $\operatorname{lnShort-season~rainfall}$ & -0.08814 & 0.1434 & -0.615 & 0.5435 & 2.018 \\
\hline $\ln$ Long-season rainfall & $-0.498^{*}$ & 0.2888 & -1.725 & 0.3252 & 1.625 \\
\hline $\operatorname{lnMinTemp}$ & 0.9149 & 0.6452 & 1.418 & 0.1669 & 2.134 \\
\hline $\operatorname{lnMaxTemp}$ & $-2.8099 *$ & 1.6121 & -1.743 & 0.6192 & 3.331 \\
\hline Coefficient of determination $\mathrm{R}^{2}$ & & 0.825 & & & \\
\hline $\mathrm{R}^{2}$-adjusted & & 0.777 & & & \\
\hline F-ratio & & $17.17 * * *$ & & & \\
\hline Multiple correlation coefficient & & 0.9085 & & & \\
\hline Residual standard deviation & & 0.1372 & & & \\
\hline Sample Size & & 38 & & & \\
\hline \multicolumn{6}{|c|}{$\begin{array}{l}* * * * * \text { and } * \text { indicates significance levels at } 1 \%, 5 \% \text { and } 10 \% \text { respectively. } \\
\text { Source: Author's computation }\end{array}$} \\
\hline $\begin{array}{l}\text { Conversely, the socioec } \\
\text { such as land area cultivated, qu } \\
\text { and irrigated area under wheat }\end{array}$ & $\begin{array}{l}\text { onomic factor } \\
\text { Iantity of fertil } \\
\text { crop all sho }\end{array}$ & $\begin{array}{l}\text { included in } \\
\text { zer used, qua } \\
\text { ed positive }\end{array}$ & $\begin{array}{l}\text { he curren } \\
\text { ntity of ir }\end{array}$ & $\begin{array}{l}\text { model est } \\
\text { aproved see }\end{array}$ & $\begin{array}{l}\text { imation } \\
\text { d used, } \\
\text { except }\end{array}$ \\
\hline
\end{tabular}


cropping showed negative and significant impact on yield of wheat crop. The result implies that any area expansion under wheat crop production would have negative impact.

The regression coefficients for quantity of fertilizers and improved seed used on wheat crop production as well as irrigated area were positive and significant at 1 percent level of significance. The results imply that use of these inputs; fertilizer, improved seed and irrigated area have vital role in increasing yields of wheat crop. The regression results in Table 3.5 show that as fertilizer consumption increases by one percent, wheat yield increases by approximately $0.27 \%$. Similarly, the regression result showed that as improved seed consumption increases by one percent, wheat yield increases by approximately $0.18 \%$. This indicates that use of improved wheat seed is among the options to increase wheat productivity in the country. On the other hand, irrigated area put under wheat cropping system have positive and significant relationship with yield of wheat crop. The result indicates that a $1 \%$ increase in irrigated area under wheat production would increases wheat yield by approximately $0.15 \%$.

The study results of input usage on wheat crop production are consistent with the findings of other researchers (Shumetie, et al, 2017; Birthal et al, 2014; Ajay and Pritee, 2013). Shumetie et al (2017) found that inorganic fertilizer had significant and positive effect on yield of wheat and barley crops, which means small unit increment in its application could enhance yield significantly. Ajay and Pritee (2013) in their study on the impact of climate variation on agricultural productivity in rural India found that any fertilizer usage increment could enhance wheat, maize, barley and sorghum productivity as well as increase in irrigated area under crop is important factor to increase wheat productivity, which was a finding corroborated with the above model result for cereal crops. Birthal et al (2014) found that irrigation has significant impact on wheat yield; the coefficient of irrigated area has been found significant and had the expected signs in wheat cropping system, implying that irrigation is important to counterbalance the harmful effects of climate change on wheat crop. Zahid (2016) in his assessment of impact of climate change on farm production in Punjab, Pakistan found that fertilizer, seed, and irrigated area have all showed positive and statistically significant at $1 \%$ level 
434 on crop productivity. The results indicate that use of these inputs is very important to 435 increase yield of crops.

436

437

438

439

440

441

442

443

444

445

446

447

448

449

\section{Conclusion}

The ultimate objective of this study was to analyze the impact of climate change on yields of wheat crop in Ethiopia using quantitative time series data for the period 1981 2018. The study adopted Cobb-Douglas Production Functional model to examine the impact of climate and non-climatic factors on yield of wheat in the country.

The findings of this study confirmed that long-season rainfall (June to September) and crop growing period (February to September) maximum temperature have negative and significant (at 1 percent level) impact on yield of wheat crop. The result implies that a rise in maximum temperature during crop growing period and change or variation in long-season rainfall could have adverse impact on yield of wheat crop in wheat growing belts. The study finding on the relationship between crop season mean maximum temperature and wheat yield is in line with the theory proposition that states a rising temperature may result in reduced agricultural productivity. With regard to long-season rainfall, the theory assumes that more variations in rainfall patterns may adversely affect yield of wheat crop. However, mean minimum temperature during crop growing season (F-S) and short-season rainfall (February to March) portrayed positive association with yield of wheat, but only mean minimum temperature is found significant at 1 percent level. Short-rain season is the period when land preparation activities for wheat crop partly take place requiring modest rainfall and minimum temperature.

The study also revealed that fertilizer, improved seed and irrigation are important factors to increase productivity of wheat crop. The study finding showed that the quantity of fertilizers and improved seed used, and irrigated area on wheat crop all have positive and significant impact on yield of wheat crop. The results imply that use of these inputs; fertilizer, improved seed and irrigation have vital role in increasing yields of wheat crop. Contrarily, the study indicated that land area cultivated under wheat cropping showed 
466 negative and significant impact on yield of wheat crop. The result implies that any area 467 expansion under wheat crop production would have negative impact. In view of findings of this study, it can be concluded that every crop has an 470 optimum minimum and maximum temperatures and rainfall limit for their reproductive 471 and vegetative growth. When temperature exceeded the upper limit, crop production 472 changes drastically. Moreover, excessive rainfall may create water logging condition and 473 flooding that also destroys crop production.

474 Given high vulnerability of wheat yields to climate variations in Ethiopia, it is 475 recommended that different adaptation strategies should be adopted to offset the adverse 476 effects of climate change. Based on the empirical findings of this study, increased use of 477 irrigation is recommended, particularly in lowland areas where potential prevails to 478 mitigate the adverse effect of climate sensitivity of wheat crop. Increase in use of 479 fertilizers and improved seed varieties that are tolerant to drought can be another option 480 to increase the productivity of wheat crop in Ethiopia. 


\section{Supplementary Files}

This is a list of supplementary files associated with this preprint. Click to download.

- ReferenceClimateVaiablesImpactingWheatYields.docx 